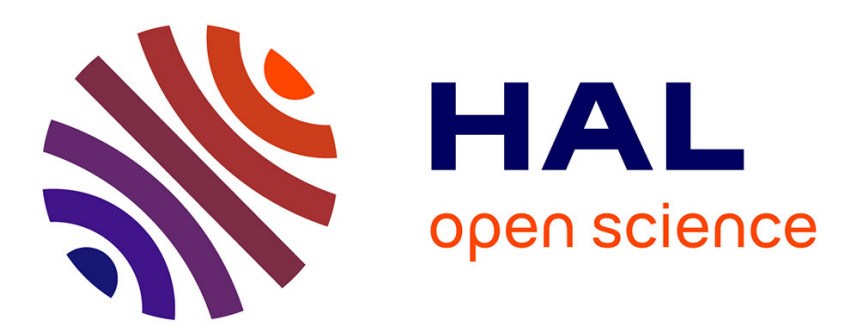

\title{
Release kinetics of an amphiphilic photosensitizer by block-polymer nanoparticles
}

\author{
Rachid Kerdous, Franck Sureau, Aurélien Bour, Stéphanie Bonneau
}

\section{To cite this version:}

Rachid Kerdous, Franck Sureau, Aurélien Bour, Stéphanie Bonneau. Release kinetics of an amphiphilic photosensitizer by block-polymer nanoparticles. International Journal of Pharmaceutics, 2015, 495 (2), pp.750-760. 10.1016/j.ijpharm.2015.09.032 . hal-01244555

\section{HAL Id: hal-01244555 \\ https://hal.science/hal-01244555}

Submitted on 19 Nov 2016

HAL is a multi-disciplinary open access archive for the deposit and dissemination of scientific research documents, whether they are published or not. The documents may come from teaching and research institutions in France or abroad, or from public or private research centers.
L'archive ouverte pluridisciplinaire HAL, est destinée au dépôt et à la diffusion de documents scientifiques de niveau recherche, publiés ou non, émanant des établissements d'enseignement et de recherche français ou étrangers, des laboratoires publics ou privés. 


\title{
Release Kinetics of an Amphiphilic Photosensitizer by Block-Polymer Nanoparticles.
}

\author{
Rachid Kerdous ${ }^{1,2}$, Franck Sureau ${ }^{1,2}$, Aurélien Bour ${ }^{1,2}$, Stéphanie Bonneau ${ }^{1,2}$ * \\ ${ }^{1}$ Université Pierre et Marie Curie-Paris 6, Laboratoire Jean Perrin - UMR8237, 4 place \\ Jussieu, Paris, F-75005 France ; \\ ${ }^{2}$ CNRS, Laboratoire Jean Perrin, UMR8237, 4 place Jussieu, Paris, F-75005 France.
}

\section{*Corresponding author}

stephanie.bonneau@upmc.fr

Permanent address:

Stéphanie Bonneau

Laboratoire Jean Perrin - UMR8237

Université Pierre et Marie Curie

Case courrier 114

4 place Jussieu

F-75005 Paris

France

Tel.: (33) 140279064

Fax: (33) 140274715

Key words:

Block-polymer nanoparticles, Drug release, Photosensitizer, Transfer, Collisions. 


\section{ABSTRACT}

Block-polymer nanoparticles are now well-known candidates for the delivery of various nonsoluble drugs to cells. The release of drugs from these nanoparticles is a major concern related to their efficiency as nanovectors and is still not completely deciphered. Various processes have been identified, depending of both the nature of the block-polymer and those of the drugs used. We focused our interest on an amphiphilic photosensitizer studied for photodynamic treatments of cancer, Pheophorbide-a (Pheo). We studied the transfer of Pheo from poly(ethyleneglycol-b- $\varepsilon$-caprolactone) nanoparticles (I) to MCF-7 cancer cells and (II) to models of membranes. Altogether, our results suggest that the delivery of the major part of the Pheo by the nanoparticles occurs via a direct transfer of Pheo from the nanoparticles to the membrane, by collision. A minor process may involve the internalization of a small amount of the nanoplatforms by the cells. So, this research illustrates the great care necessary to address the question of the choice of such nanocarriers, in relation with the properties - in particular the relative hydrophobicity - of the drugs encapsulated, and gives elements to predict the mechanism and the efficiency of the delivery.

\section{GRAPHICAL ABSTRACT}

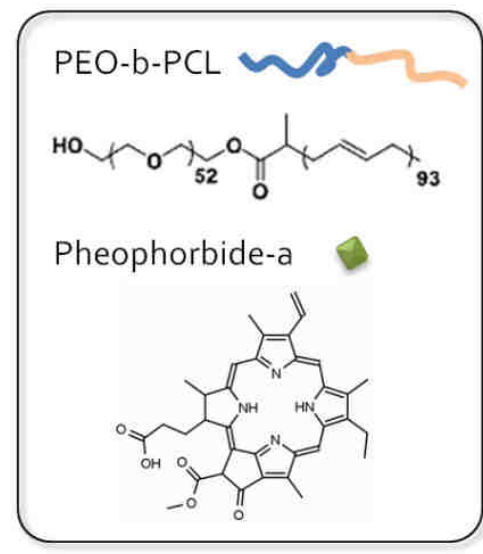

\section{BLOCK POLYMER NANOPARTICLES}

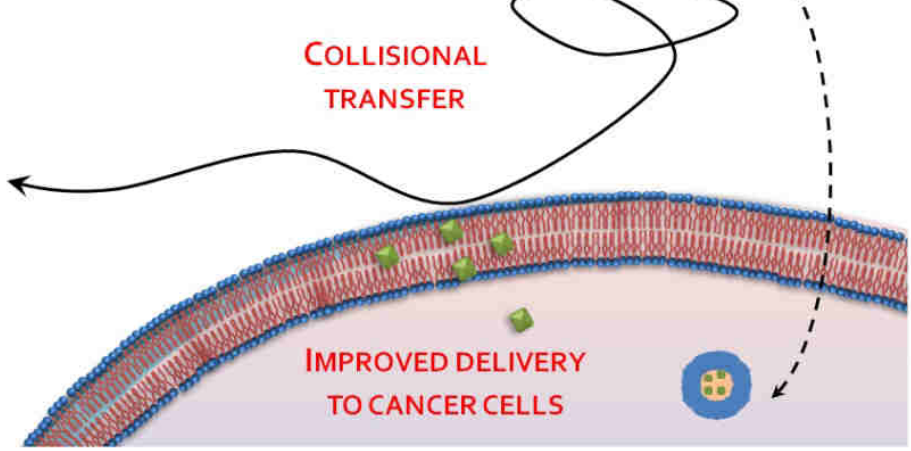

PEO-PCL nanoparticles improve delivery to cancer cells via direct transfer to the membrane by collision. 


\section{1- INTRODUCTION}

The therapeutic use of photosensitizing drugs is based on the light-induced generation of reactive oxygen species that damage surrounding biological structures (Spikes, 1982). These therapies are based on the use of photosensitizers, non-toxic in the dark but capable of generating, under light irradiation, active molecular species such as free radicals and singlet oxygen that are toxic for the biological environment. In terms of medical indications, the potential of these techniques is related to the capability of a number of photosensitizer to accumulate selectively in proliferating tissues, and has been improved by the development of laser diodes and optical fibers (van den Bergh, 1998). The photosensitizers are used in the clinical treatment of several oncologic and ophtalmologic diseases (Ackroyd et al., 2001; Brown et al., 2004; Levy and Obochi, 1996; Miller et al., 1999). The major advantage of these techniques, named photodynamic therapies (PDT) is their dual-selectivity, resulting from both (i) the positive ratio of photosensitizer accumulation between proliferating and normal surrounding tissues and (ii) the possibility to restrict the light irradiation to the diseased area (Dougherty, 1985; Dougherty et al., 1998). However, the particular photophysical properties of the photosensitizers are related to their macrocycles, and one important limitation for their biomedical uses is due to their consequent amphiphilic or hydrophobic nature. Such drugs require delivery systems able to limit self-assembly and aggregation in aqueous physiologic medium. If this problem occurs for all water-insoluble drugs and involves important problems of administration, cellular incorporation and pharmacokinetics, it is of particular importance in the context of photodynamic therapy, based on the specific photophysical properties of the photosensitizers, that are lost upon aggregation of the dye.

Synthetic vectors such as liposomes and polymeric nanoparticles are increasingly developed for drug delivery, with the goal to solve the solubility-related problems previously mentioned, to improve the biocompatibility of drug delivery systems, protect the therapeutic payload from degradation, delay uptake by the reticuloendothelial system (Wattendorf and Merkle, 2008), enhance the crossing of biological barriers, and efficiently transfer the drug to the target. In this context, improvements of PDT strategies have been obtained by using appropriate formulations (Cremaphor) and nanocarriers able to accumulate within tumors trough the enhanced permeation and retention (EPR) effect, such as liposomes (Derycke and de Witte, 2004; Kuntsche et al., 2010) or nanoparticles (Couleaud et al., 2010; Li et al., 2007).

Amphiphilic block copolymer nanoparticles are stable frozen micelles with a diameter between 10 and $100 \mathrm{~nm}$ (Kazunori et al., 1993). Their structure exhibit an hydrophobic core able to incorporate drugs, surrounded by a hydrophilic corona ensuring the stability of the micelle ( Allen et al., 1999a). This enables them to increase the solubility of hydrophobic compounds (Kim et al., 2011; Liu et al., 2004; Stenzel, 2008; Uhrich et al., 1999). Like other synthetic vectors, they can be designed to handle organism barriers and self-defense (Luo et al., 2002; Owens and Peppas, 2006). Consequently, as nano-scaled delivery platforms, they can be utilized to accumulate the drug in cancerous tissues by EPR effect (Konan et al., 2002; Maeda et al., 2000). As promising vectors, many studies question their effects on solubility, pharmacokinetics and the biodistribution of drugs (Albertsson and Varma, 2003; Kim et al., 2010; Wei et al., 2009; Yokoyama, 2010). Nevertheless, one key point of their efficiency is the mechanism of drug delivery to the cells, which is still not well understood for such stable frozen nanoparticles. Various processes have been proposed. For instance, fluorescent poly(ethyleneoxide-b-e-caprolactone) (PEO-PCL) copolymer nanopaticles have been 
suggested to enter the cells by endocytosis (Allen et al., 1999b) and have also been reported to distribute in various intracellular organelles - lysosomes, Golgi aparatus, endoplasmic reticulum and mitochondria (Savic et al., 2003). In contrast, similar nanoparticles, made of (polyethylene glycol)-b-poly (D, L-lactide) (PEG-PDLLA), have been reported to be unable to penetrate into the cells but to transfer the entrapped drug through the plasma membrane, leading to the internalization of the drug (Chen et al., 2008). The mechanism of penetration remains then uncertain.

In this paper we decipher the drug delivery mechanism for one promising type of nanoparticles, made of poly(ethylene oxide)-poly( $\varepsilon$-caprolactone) [PEO(5000)-PCL(4000)]. The entrapped drug, pheophorbide-a (Pheo), is a photosensitizer, the presence of which can be reported by the direct fluorescence of the compound. The uptake by MCF-7 cancer cells was first evaluated by fluorescence microscopy and extraction, and the intracellular localization studied over time. To decipher the involved mechanisms, the transfer to membrane models (Large Unilamellar Vesicles) was then studied by fluorescence spectroscopy and discussed paying a particular attention to the dynamics of the processes.

\section{2- MATERIAL AND METHODS}

\section{Chemical materials}

Poly(ethyleneoxide-b- $\varepsilon$-caprolactone) [PEO(5000)-b-PCL(4000)] (figure 1) were purchased from Gearing Scientific. Pheo (fig 1) was purchased from Frontier Scientific (Logan UT, USA). Photosensitizer stock solutions were prepared in ethanol. Experimental solutions were handled in the dark. Dioleoylphosphatidylcholine (DOPC) and L- $\alpha$ phosphatidylethanolamine-N-(lissamine rhodamine B sulfonyl) (Lip-Rho) were obtained from

Avanti Polar Lipids (USA). 1,1'-Dioctadecyl-3,3,3',3'-tetramethylindocarbocyanine perchlorate (DilC, figure 1) and 3,3'-Dioctadecyloxacarbocyanine perchlorate (DiOC, figure 1) fluorophores were obtained from Invitrogen Life Technologies (Saint Aubin, France). All other chemicals were purchased from Sigma (USA).

\section{Fluorescence microscopy.}

The instrumental set-up was based on a Nikon Eclipse TE 300 DV inverted microscope equipped with a high-numerical aperture phase-oil objective (CFI Plan apochromat DM $\times 60$ n.a.: 1.4, Nikon France). A $120 \mathrm{~W}$ metal halide lamp was used for fluorescence excitation. The mercury rays were isolated with narrow-band interference filters mounted on a filter wheel positioned along the excitation path (Sutter Instrument Company). If necessary, neutral density filters $(N D \times 8)$ were used to reduce the excitation level. Image acquisition (1000 ms integration time) was performed with a CoolSNAP HQ2 (Roper Scientific France). Data acquisition and processing were performed with Metamorph software supplied by Universal Imaging Corporation (Roper Scientific, France).

Time resolved microspectrofluorimetry.

105 Our original fluorescent confocal microscope set-up enables concomitants spectroscopic and excited state lifetime measurements of the fluorescence emission signal. A frequency domain phase-modulation method appears to be particularly appropriate for rapid and noninvasive measurements of fluorescence lifetime on single living cells. The precise description of the set-up has already been published (Petr Praus, 2007). Briefly, the $50 \mathrm{~mW}$ output power laser diode module (LDM 442.50.A350 from Omicron) is used for excitation at 442 
$\mathrm{nm}$. Modulation frequencies are ranging from 10 to $200 \mathrm{MHz}$. A Zeiss UMSP-80 confocal epifluorescence upright microscope is used with a high numerical aperture water-immersion 63x magnification objective (Zeiss Neofluar, N.A. 1.2). A Jobin Yvon HR640 monochromator is used for dispersion of the fluorescence signal $(10 \mathrm{~nm} / \mathrm{mm})$. Thus a $350 \mathrm{~nm}$ spectral region can be focused on the intensified digital CCD camera (Lambert Instruments, Roden, Netherlands) used for detection. A control unit drives the frequency and amplitude values of the RF modulation signals delivered by two synthesizers (model 2025 from IFR, Hertfordshire, UK) to the diode laser light source and to the image intensifier of the camera, respectively. It also induces precise phase shifts between the output signals of both synthesizers. The LIFLIM software (Lambert Instruments) is used for data acquisition. Data processing for lifetime determination is performed by global fitting with LevenbergMarquard algorithm. The most severe limitation for the emission intensity is due to photobleaching in the sample (Hoebe et al., 2007)). Hence, the $50 \mathrm{~mW}$ output power of the laser diode module is first attenuated (from $1 / 100$ to $1 / 10.000$ ) by using neutral optical 125 density filters. Further attenuations, through optics of the excitation pathway (lens, mirrors, interferential filter, and semi-transparent slide), lead to a measurable excitation power of only $0.1-1 \mu \mathrm{W}$ at the sample level.

\section{Preparation of the loaded nanoparticles.}

The preparation of the nanoparticles was performed as previously described (Knop et al., 2009). Briefly, twenty milligrams of the polymer was dissolved in $0.4 \mathrm{~mL}$ of acetone, and this acetone polymer solution was dispersed dropwise into $5 \mathrm{~mL}$ of ultrapure filtered water (filtered on $0.2 \mu \mathrm{m} \mathrm{RC}$ filters). To remove the acetone, the solution was then left standing for 2 days. Loading of the micelles with photosensitizer (or Dilc/DiOC fluorophores, used in some experiments) was done by adding the latter to the initial polymer acetone solution.

135 The Pheo/PEO-PCL ratio being kept at 1/50. In previous studies, the characterization of our block-polymer nanoparticles has been performed (Ehrhart et al., 2011; Gibot et al., 2014). Their hydrodynamic diameters have been determined by Dynamic Light Scattering (DLS) and are ranged between 24.6 and $27.1 \mathrm{~nm}$, depending on the nature of the entrapped compounds. The spherical shape of the polymeric nanoparticles was determined by Transmission Electron Microscopy (TEM).Their stability upon dilution and aging, even in presence of serum (FBS) and membranes (lipid vesicles) has also been demonstrated.

\section{Assessment of the stability of the nanoparticles}

The stability of the nanoparticles in our experimental conditions was examined by FRET experiments, using two probes, DilC and DiOC, according with the method used in [33]. The nanoparticles were prepared as previously mentioned in the presence of both probes, ensuring their encapsulation and the appearance of FRET. This involves both (i) a decrease of the fluorescence band of DiOC at $503 \mathrm{~nm}$ in favor of that of DilC at $567 \mathrm{~nm}$ and (ii) changes in the fluorescence lifetime of the donnor (see results). Therefore, the ratio between the two fluorescence bands, as well as the corresponding lifetime modifications, are direct indications of the proximity of both probes, what signs their encapsulation and the stability of the nanocarrier. For in vitro experiments, the fluorescence spectra were measured with an Aminco Bowman Series 2 spectrofluorimeter (Edison, NJ, USA). To begin the stability follow up, $50 \mu \mathrm{l}$ of nanoparticles solution was added to $1.95 \mathrm{~mL}$ of the tested solution (buffer or LUV), corresponding to a dilution of $1 / 40$. The fluorescence spectra (excitation at $470 \mathrm{~nm}$ ) were recorded versus time from 0 to 200 minutes after dilution. The FRET efficiency, estimated using the fluorescence ratio, $F_{567} /\left(F_{567}+F_{507}\right)$, was followed and plotted (Figure S1). 
For in cellulo experiments, the fluorescence spectra and the lifetimes of both dyes were recorded with our original time resolved microspectrofluorimeter.

\section{Cell line and cell culture}

160 MCF-7 breast cancer cells (ATCC) were grown at $37{ }^{\circ} \mathrm{C}$ in RPMI medium supplemented with $5 \%$ fetal bovine serum (FBS) and $100 \mathrm{U} / \mathrm{mol}$ penicillin/streptomycin. The incubator contained a humidified atmosphere of air and $5 \% \mathrm{CO}_{2}$. Cells were subcultured at $75 \%$ confluence, when the cell density reached an average of $2 \times 10^{5}$ cells $/ \mathrm{cm}^{2}$.

\section{Subcellular localization of the Pheo}

165 Cells were seeded on a $0.17 \mathrm{~mm}$ thick cover glass two days before experiments. Then, the cover glass was washed with Hank's balanced salt solution (HBSS), and cells were incubated with Pheo in the same media for $30 \mathrm{~min}, 1 \mathrm{~h}, 2 \mathrm{~h}$ or $4 \mathrm{~h}$ at $37^{\circ} \mathrm{C}$. Pheo was used alone or preloaded in nanoparticles (ratio $1 / 50$ ) at a concentration of $10^{-7}$ and $10^{-6} \mathrm{M}$. Control experiments were performed with the same protocol but without photosensitizer. In all cases, cells were washed twice with HBSS after incubation. After treatment, the red fluorescence emission of Pheo was collected through a band-pass filter $(645 \pm 75 \mathrm{~nm}$, Omega). A band-pass filter (330-380 nm) and a dichroic mirror at $400 \mathrm{~nm}$ were used for excitation. All experimental conditions were performed in triplicates.

\section{Quantification of photosensitizer uptake}

175 MCF-7 cells were seeded $24 \mathrm{~h}$ before the experiments in 35-mm Petri dishes. Cells were used at about $5 \times 10^{4}$ cells $/ \mathrm{cm}^{2}$. After the same incubation protocol, cells were washed twice with 1 $\mathrm{mL}$ HBSS and then scrapped in $900 \mu \mathrm{L}$ pure water to lyse cells. Disrupted cells were collected and added to $100 \mu \mathrm{L}$ of an aqueous solution containing 3\% Triton X-100. In these conditions, Pheo is monomeric, and its fluorescence is directly proportional to its concentration. Then, $150 \mu \mathrm{L}$ was saved for protein determination according to the Lowry method. The remaining solution was used for fluorimetric measurement of Pheo concentrations. Solutions of known photosensitizer concentrations were used as standards. Data are expressed in moles of Pheo per gram of protein and are the mean ( \pm S.D.) of triplicate experiments.

\section{Membrane models preparation}

185 DOPC stock solutions were made in chloroform and stored under argon atmosphere at $18^{\circ} \mathrm{C}$. Large Unilamellar Vesicles (LUVs) were prepared by extrusion. After evaporation of chloroform, lipids were dispersed in phosphate buffer $\mathrm{pH} 7.4$ by vortexing. The liposome suspension was extruded 8-10 times through a stack of two polycarbonate membrane filters (Poretics, Livermore, CA) with pores of $100 \mathrm{~nm}$ using an extruder device (Avanti Polar Lipids, USA).

\section{Steady-state interactions}

For the steady-state study of the interaction of Pheo with LUVs, fluorescence spectra were measured with an Aminco Bowman Series 2 spectrofluorimeter (Edison, NJ, USA). LUVs solutions were prepared at different concentrations of lipids. Pheo solutions were added to the LUVs preparation and the fluorescence spectra were recorded. Recording was started when the equilibrium was reached (see kinetics results). In order to correct the spectra for small differences in Pheo concentration arising from experimental inaccuracy, Triton-X100 was added after measurement leading to the disruption of vesicles and the solubilization of all Pheo in the Triton micelles. The spectra were normalized accordingly. The interaction of 
the Pheo with nanoparticles was studied with the same approach by recording fluorescence spectra of the Pheo in preparations of different concentrations of nanoparticles.

Data thus obtained were treated as described elsewhere (Kerdous et al., 2011; Kuzelová and Brault, 1994). The global binding constants were derived from changes in the fluorescence signal at a wavelength corresponding to the maximum of fluorescence emission of Pheo incorporated into the membrane (or into the core of the PEO-PCL nanoparticles in the case of the study of the interaction of pheo with these nanocarriers).

\section{Kinetic measurements}

The kinetic measurements were performed by using an Applied Photophysics (Leatherhead, UK) stopped-flow apparatus with mixing time of $1.2 \mathrm{~ms}$. The mixing ratio between both solutions was $1 / 1 \mathrm{v} / \mathrm{v}$. The excitation light provided by a $150 \mathrm{~W}$ xenon arc lamp was passed through a monochromator with slits generally set to give a spectral bandwidth of $4.65 \mathrm{~nm}$. Fluorescence emission was collected using a low-cut filter (Oriel, France). The fluorescence signal was fed into a RISC workstation (Acorn Computers, UK) and treated using the software provided by the manufacturer. Slow kinetic measurements were performed with an Aminco Bowman spectrofluorimeter.

\section{3- RESULTS}

\section{1- Cellular delivery of the Pheo molecules encapsulated within PEO-PCL nanoparticles.}

The cellular uptake of the Pheo was first studied by fluorescence microscopy. MCF-7 cancer cells were incubated with the photosensitizer preloaded or not in nanoparticles. In all cases, regardless of the incubation time and the concentration of Pheo, cells exhibit a granular perinuclear fluorescence and a labeling of the plasma membrane (Figure 2). Importantly, block-polymer nanoparticles do not affect the subcellular distribution of the Pheo. The average red fluorescence intensity of the cell-body was quantified with ImageJ software and was plotted vs. time in figure 2B. Typically, the cells incubated with the encapsulated Pheo are two times more labeled than those incubated with Pheo alone (for example, $1780 \mathrm{cpm}$ vs. $750 \mathrm{cpm}$ for $0.5 \mathrm{~h}$ incubation of Pheo $10^{-6} \mathrm{M}$ ). This suggests that the nanoparticles promote an increase of the cellular delivery.

To follow the kinetics of the uptake of Pheo by cells, the fluorescence was imaged over time. Its increase exhibits one single phase with a rate of $3 \times 10^{-4} \mathrm{~s}^{-1}$ when the cells are incubated with the free Pheo. For the encapsulated photosensitizer, two phases are involved: a fast one, of high amplitude ( 70\%), with a rate of $1.6 \times 10^{-3} \mathrm{~s}^{-1}$, and a slow one of small amplitude at $1.3 \times 10^{-4} \mathrm{~s}^{-1}$. To confirm these results, the Pheo taken by cells has also been quantified by extraction and fluorimetric dosage (Figure 2C). Then, its solubilization in Triton-X100 ensure its monomerization and the quantitative significance of the data. The rate values are summarized in table 1.

The increased uptake of Pheo encapsulated within PEO-PCL nanoparticles by cells may be explained by different mechanisms, which may or not involve the cellular internalization of the nanoparticles. To distinguish between them, the cellular incorporation of the nanoparticles was then followed, by recording the fluorescence of nanoparticles labeled with DilC and DiOC (which remains encapsulated as long as the nanoparticles remain stable, see stability paragraph). Our aim was to report the nanoparticles uptake and localization by imaging the fluorescence of the acceptor, DilC directly excited at $550 \mathrm{~nm}$, and their integrity 
by following the FRET efficiency. MCF-7 cells were incubated with loaded nanoparticles $\left(5 \times 10^{-5} \mathrm{M}\right)$ for 0.5 to $4 \mathrm{~h}$, and experiments were performed in triplicates.

In our experimental conditions (incubation ranged between 0 and $4 \mathrm{~h}$ ), the intracellular fluorescence intensity of the DilC was too weak to be detected with the CoolSNAP camera: it could not be distinguished from the autofluorescence of the cells. This indicates that the nanoparticles do not enter the cells efficiently. As imaging the fluorescence of the nanoparticles was not possible, we performed some experiments based on lifetime, recorded with our original set-up (see material and methods section). This allowed us to distinguish between the dyes fluorescence and autofluorescence. The spectra of nanoparticles loaded with the couple DilC/DiOC and the corresponding lifetimes are given in Figure 3, and lifetimes are summarized in table 2. Figure 3A shows the typical spectrum of a solution of loaded nanoparticles in cell culture media, and evidences the FRET between encapsulated DilC and DiOC. After $4 \mathrm{~h}$ of incubation with cells, some very weak intracellular signals, suggesting a weak incorporation of the nanoparticles, could be recorded within less than $10 \%$ of the cells (Figure 3C). Anyway, the major part of the cells were free of labeling, and the few intracellular fluorescence signals obtained were too weak to give significant spectra, neither measurements of the corresponding fluorescence lifetimes. These results support and strengthen the idea that even after $4 \mathrm{~h}$ incubation the PEO-PCL nanoparticles are not efficiently taken by the MCF-7 cells. At longer incubation times (24h), the relatively higher intensity of the fluorescence allows to determine a lifetime of the DiOC that reaches 1 ns (instead of 0.5 ns when well-encapsulated, see figure 3B). This may correspond to a slightly larger uptake and to the some destabilization of the nanoparticles by the cells, after $24 \mathrm{~h}$ of incubation. This uptake of nanoparticles stays, in all conditions, very poor.

The photosensitizer is thus efficiently incorporated, but not the nanoparticles. The subcellular localization of the Pheo is poorly modified by its encapsulation within PEO-PCL nanoparticles. The relative discrepancy between this increased cellular internalization of Pheo molecules and the weak and slow uptake of the nanoparticles has to be questioned. Another insight can be obtained from the comparison of the kinetics of these processes. The small cellular entry of the nanoparticles was time-dependent, and equilibrium was not reached within 24 hours of incubation. In contrast, internalization of encapsulated Pheo increase sharply and reached a plateau after 1 hour of incubation (Figure 2B-C). There were 275 two phases. One phase was rapid and had a high amplitude. The other phase was slow with small amplitude. This suggests that cellular penetration of encapsulated Pheo in nanoparticles involves at least two mechanisms. One mechanism is fast and corresponds to cellular uptake of the major part of the Pheo. The other mechanism is slow and may be related to the slow and weak cellular internalization of nanoparticles. Altogether, our

280 cellular results strongly suggest that the major part of the Pheo loaded in nanoparticles does not enter into cells in the encapsulated form.

At this point, it is reasonable to determine if this effect is due to the dissociation of the block-polymer nanoparticles in cell culture media. This possibility was suggested by (Chen et al., 2008). Here, the stability of PEO-PCL nanoparticles, examined by FRET experiments, 285 shows that nanoparticles remain stable in our media, as well as within cells cultures during hours. Moreover, their stability has been reported in the presence of proteins and FBS at around $10-12 \%$ over a $24 \mathrm{~h}$ period at room temperature [33]. Therefore, dissociation of PEOPCL nanoparticles does not occur before the penetration of Pheo molecules within cells. 
The main transfer of Pheo from nanoparticles to cells does not involve the uptake of nanocarriers and is not due to their dissociation. The transfer of the drug to the cell membranes may then occur by diffusion of the Pheo through the aqueous phase (diffusion model) or by its direct transfer from the nanoparticles to the membrane during Brownian collisions (collision model, Figure 4A). To assess each of these hypotheses, we studied the transfer of Pheo from PEO-PCL nanoparticles to simple membrane-mimicking systems (LUVs) by following changes in Pheo fluorescence.

\section{2- Transfer of Pheo from pre-loaded PEO-PCL nanoparticles to membrane-mimicking systems.}

The dynamics of the processes involved within this transfer have been carefully studied. The fluorescence of Pheo is strongly sensitive to the environment of the molecule and the emission spectra appear to be different enough to easily monitor changes in the photosensitizer environment (Figure 4B), and the variations in the rates of the transfer when the vesicles concentration is increased allow to distinguish between the two proposed mechanisms.

\subsection{1- Kinetic models}

The rate constants mentioned in figure 4 and corresponding to the interaction of the Pheo with the LUVs on the one hand and with the PEO-PCL nanoparticles on the other hand, can be determined by the follow up of the interactions of the photosensitizer with these two objects. For the LUVs-Pheo interaction studies, the kinetic datas were analyzed according to a theoretical model previously described elsewhere (Kuzelová and Brault, 1994). Briefly, the association of Pheo with vesicles involves two steps. First, it enters into the outer leaflet of the bilayer. The second step involves the transfer of the Pheo through the bilayer that results in an equilibrated partition between the two leaflets. Amphiphilic molecules bearing polar chains with asymmetrical distribution such as Pheo become localized in the two hemileaflets with their polar moiety oriented towards the aqueous interfaces. In these conditions, the two steps can be distinguished. A theoretical description of these processes has been proposed (Kuzelová and Brault, 1994), according to the scheme given in figure 5A, where $P_{F}$ represents the Pheo free in the bulk aqueous solution, $P_{V}$ the Pheo associated to the LUVs which correspond to the sum of $\mathrm{Po}_{\mathrm{O}}$ and $\mathrm{P}_{\mathrm{i}}$, the Pheo incorporated into the outer leaflet or the inner one, respectively. In the present and former studies, the phospholipid concentration largely exceeds that of the photosensitizer. Hence, the entry into the vesicles obeys pseudo-first order kinetic with a constant $k_{o n}{ }^{\prime}=k_{o n}$.[lip], where [lip] is the concentration of lipids. The theoretical calculations, given in (Kuzelová and Brault, 1994), predict that the experimental signal of $P_{v}$ is biexponential with rate $k_{1}$ and $k_{2}$ :

$\mathrm{k}_{1}=\mathrm{k}_{\mathrm{on}} \times[\mathrm{Lip}]+\mathrm{k}_{\text {off }}+\mathrm{k}_{\text {flip }}$

$\mathrm{k}_{2}=\mathrm{k}_{\text {flip }}$

where $\mathrm{k}_{\text {flip }}=\mathrm{k}_{\mathrm{ti}}+\mathrm{k}_{\mathrm{to}}$

The kinetics of Pheo interaction with nanoparticles was simpler. Only one phase was observed, giving a $k_{a s}$ value and a $k_{\text {dis }}$ value for the rate constants of association and dissociation, respectively. 
Then, we examined the kinetics of the transfer of Pheo preloaded in PEO-PCL nanoparticles to membrane models. The variations in the rate constants with respect to the concentrations of nanoparticles and LUVs are used to distinguish between a collisional and a diffusional mechanism of the Pheo transfer. In a first approximation, we assume that binding of any molecule does not depend on the state of its acceptor occupancy. In other words, pseudo-first-order conditions are assumed, in accordance with the experimentally used concentrations.

Assuming that the transfer occurs by diffusion, the set of differential equations describing the system is:

$\frac{\mathrm{dP}_{\mathrm{v}}}{\mathrm{dt}}=\mathrm{k}_{\mathrm{on}}^{\prime} \cdot \mathrm{P}_{\mathrm{F}}-\mathrm{k}_{\mathrm{off}} \cdot \mathrm{P}_{\mathrm{v}}$

$$
\begin{aligned}
& \frac{\mathrm{dP}_{\mathrm{F}}}{\mathrm{dt}}=\mathrm{k}_{\mathrm{dis}} \cdot \mathrm{P}_{\mathrm{NP}}+\mathrm{k}_{\text {off }} \cdot \mathrm{P}_{\mathrm{V}}-\left(\mathrm{k}_{\mathrm{as}}^{\prime}+\mathrm{k}_{\mathrm{on}}^{\prime}\right) \mathrm{P}_{\mathrm{F}} \\
& \frac{\mathrm{dP}_{\mathrm{NP}}}{\mathrm{dt}}=\mathrm{k}_{\mathrm{as}}^{\prime} \cdot \mathrm{P}_{\mathrm{F}}-\mathrm{k}_{\mathrm{dis}} \cdot \mathrm{P}_{\mathrm{NP}}
\end{aligned}
$$

where $P_{F}$ represents the free aqueous concentrations of Pheo, $P_{V}$ and $P_{N P}$ are the concentrations of the Pheo associated to the vesicles and the nanoparticles, respectively. $\mathrm{k}_{\mathrm{on}}^{\prime}$ and $\mathrm{k}_{\mathrm{as}}^{\prime}$ are apparent association rate constants according to:

$\mathrm{k}_{\mathrm{on}}^{\prime}=\mathrm{k}_{\mathrm{on}} \times[\mathrm{lip}]$

$\mathrm{k}_{\mathrm{as}}^{\prime}=\mathrm{k}_{\mathrm{as}} \times[\mathrm{PEO}-\mathrm{PCL}]$

where $[\mathrm{PEO}-\mathrm{PCL}]$ is the concentration of nanoparticles expressed as a function of the PEOPCL content.

350 However, a considerable simplification can be obtained by considering the experimental conditions which will prevail in our study. Indeed, owing to the high concentrations of vesicles and nanoparticles used, the rates for the association of Pheo with nanoparticles or vesicles are much larger than the exit rates to aqueous solution. The concentration of the free form $\left(P_{F}\right)$ will then remain very low. In these conditions, the steady-state method of Bodenstein (Benson, 1960) holds, i.e., with the exception of a short initial period, $\mathrm{dP}_{\mathrm{F}} / \mathrm{dt}=$ 0 . We can thus express $P_{F}$ :

$$
\mathrm{P}_{\mathrm{F}}=\frac{\mathrm{k}_{\text {off }} \cdot \mathrm{P}_{\mathrm{V}}+\mathrm{k}_{\mathrm{dis}} \cdot \mathrm{P}_{\mathrm{NP}}}{\mathrm{k}_{\text {on }}^{\prime}+\mathrm{k}_{\text {as }}^{\prime}}
$$

The system (Eq. 2) is then transformed into:

$$
\frac{\mathrm{dP}_{\mathrm{V}}}{\mathrm{dt}}=-\alpha \mathrm{P}_{\mathrm{V}}+\beta \mathrm{P}_{\mathrm{NP}}
$$

$$
\frac{\mathrm{dP}_{\mathrm{NP}}}{\mathrm{dt}}=\alpha \mathrm{P}_{\mathrm{V}}-\beta \mathrm{P}_{\mathrm{NP}}
$$

where $\alpha=-\frac{\mathrm{k}_{\mathrm{as}}^{\prime} \cdot \mathrm{k}_{\text {off }}}{\mathrm{k}_{\mathrm{on}}^{\prime}+\mathrm{k}_{\mathrm{as}}^{\prime}}$ and $\beta=\frac{\mathrm{k}_{\mathrm{on}}^{\prime} \cdot \mathrm{k}_{\mathrm{dis}}}{\mathrm{k}_{\mathrm{on}}^{\prime}+\mathrm{k}_{\mathrm{as}}^{\prime}}$ 
The solution can be found by using Laplace transforms (Connors, 1990). With the initial conditions, corresponding to our experimentations, i.e. $P_{N P}=P_{0}$, and $P_{V}=0$, the system is transformed into:

$\mathrm{s} \mathscr{P}_{N P}-\mathrm{P}_{0}=\alpha \mathscr{P}_{V}-\beta \mathscr{P}_{N P}$

$\mathrm{s} \mathscr{P}_{\mathrm{V}}=-\alpha \mathscr{P}_{V}+\beta \mathscr{P}_{N P}$

where $\mathrm{s}$ stands for the Laplace transform of the derivative function, and $\mathscr{P}_{N P}$ and $\mathscr{P}_{V}$ for the Laplace transforms of $\mathrm{P}_{\mathrm{NP}}$ and $\mathrm{PV}$.

The inverse Laplace transforms yield the time dependence of the concentrations. Monoexponential functions with the rate constant $k$ are obtained for the two species. This rate constant is:

$\mathrm{k}=\frac{1}{2}(\alpha+\beta)=\frac{\mathrm{k}_{\mathrm{as}}^{\prime} \cdot \mathrm{k}_{\mathrm{off}}+\mathrm{k}_{\mathrm{on}}^{\prime} \cdot \mathrm{k}_{\mathrm{dis}}}{\mathrm{k}_{\mathrm{on}}^{\prime}+\mathrm{k}_{\mathrm{as}}^{\prime}}$

The expected experimental signal is then monoexponential with a rate, $k$, which is an increasing function of the lipids concentration. This function is bounded by a supremum 375 given by:

$\mathrm{k}_{\mathrm{MAX}}=\lim _{[l i p] \rightarrow \infty} \frac{\mathrm{k}_{\mathrm{as}}^{\prime} \cdot \mathrm{k}_{\mathrm{off}}+\mathrm{k}_{\mathrm{on}}^{\prime} \cdot \mathrm{k}_{\mathrm{dis}}}{\mathrm{k}_{\mathrm{on}}^{\prime}+\mathrm{k}_{\mathrm{as}}^{\prime}}=\frac{\mathrm{k}_{\mathrm{on}}^{\prime} \cdot \mathrm{k}_{\mathrm{dis}}}{\mathrm{k}_{\mathrm{on}}^{\prime}}=\mathrm{k}_{\mathrm{dis}}$

If it occurs by diffusion through the aqueous phase, the experimental rate of the transfer of the Pheo must then not exceed $\mathrm{k}_{\mathrm{dis}}$.

If the transfer occurs by collisions, we also assume, regarding our experimental concentrations, that the $\mathrm{P}_{\mathrm{F}}$ will remain negligible. Moreover, the experimental approach does not allow the distinction between $P_{V}$ and NP-P-V. Consequently, a simplified description of the phenomenon can be proposed, corresponding to a monoexponential decrease of the Pheo associated to the nanoparticles (Loew et al., 2011), according with the scheme:

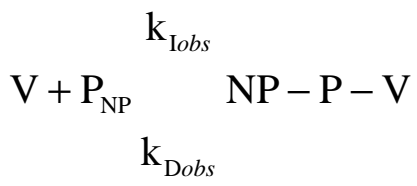

It follows that the signal corresponding to the transfer of Pheo from nanoparticles to vesicles is expected to be monoexponential with a rate constant, $k$, given by:

$$
\mathrm{k}=\mathrm{k}_{\mathrm{I} o b s} \cdot[\mathrm{lip}]+\mathrm{k}_{\mathrm{D} o b s}
$$

In that case, unlike for the diffusion model, the rate constant is not a bounded function and increases linearly with the lipids concentration.

\subsection{2- Experimental measurements}

First, the interaction of the Pheo with LUVs, used as membrane models, was examined. Addition of LUVs ([lip] $=0$ to $\left.6 \times 10^{-6} \mathrm{M}\right)$ caused the fluorescence intensity of Pheo $\left(3.75 \times 10^{-8}\right.$ M) at $676 \mathrm{~nm}$ to increase significantly, allowing us to track the transfer of Pheo from an 
aqueous to lipid environment. The fluorescence intensity at $676 \mathrm{~nm}$ versus the lipid concentration showed a saturation shape (Figure $5 \mathrm{~B}$ ). The binding constant value, $\mathrm{K}_{\mathrm{L}}$ was determined by fitting the experimental points as described (Kerdous et al., 2011; Kuzelová and Brault, 1994). Pheo exhibited a high affinity for membrane models, in accordance with other data previously obtained (Mabrouk et al., 2010). The $K_{L}$ value was to $(1.14 \pm 0.05) \times 10^{6}$ $\mathrm{M}^{-1}$ with:

$$
\mathrm{K}_{\mathrm{L}}=\frac{\mathrm{P}_{\mathrm{V}}}{\mathrm{P}_{\mathrm{F}} \cdot[\text { lip }]} \text { and } \mathrm{F}-\mathrm{F}_{0}=\frac{\left(\mathrm{F}_{\infty}-\mathrm{F}_{0}\right) \cdot \mathrm{K}_{\mathrm{L} \cdot[\text { lip }]}}{1+\mathrm{K}_{\mathrm{L}} \cdot[\text { lip }]},
$$

where $F$ is the fluorescence intensity at $676 \mathrm{~nm}, \mathrm{~F}_{0}$ and $\mathrm{F}_{\infty}$ respectively those corresponding to an absence and an excess of lipids in the sample.

405 The kinetics of this interaction was also studied according to the theoretical model previously described (Figure 5 and Eq.1). The Pheo concentration was maintained at $3.75 \times 10^{-8} \mathrm{M}$, and lipid concentrations varied from $0.5 \mu \mathrm{M}$ to $6 \mu \mathrm{M}$. After mixing, fluorescence changes were registered over time and fitted by a biexponential function (Figure $5 \mathrm{C}$ ), which generated the rate constants $\mathrm{k}_{1}$ and $\mathrm{k}_{2}$. The experimental rate constants were then plotted as a function of the lipid concentration, and the values of $k_{\text {on }}, k_{\text {off }}$, and $k_{\text {flip }}$ were given by Eq. (1): $\mathrm{k}_{\text {on }}=(5.85 \pm 0.4) \times 10^{2} \mathrm{M}^{-1} \mathrm{~s}^{-1} ; \mathrm{k}_{\text {off }}=(3.35 \pm 0.5) \times 10^{-4} \mathrm{~s}^{-1} ; \mathrm{k}_{\text {flip }}=(5 \pm 0.6) \times 10^{-4}$ $\mathrm{s}^{-1}$. These values are in good accordance with those obtained for similar photosensitizers (Mojzisova et al., 2007a, 2007b).

Then, the association constant of Pheo to PEO-PCL nanoparticles was studied in the same manner as it was for lipid vesicles. The fluorescence intensities of Pheo solutions $\left(7.5 \times 10^{-7}\right.$ $\mathrm{M})$ were recorded in samples of increasing nanoparticle concentration ([PEO-PCL] $=0$ to $\left.8.5 \times 10^{-5} \mathrm{M}\right)$. The constant $\mathrm{K}_{\mathrm{NP}}$ was $(1.07 \times 0.20) \times 10^{5} \mathrm{M}^{-1}$. The association and dissociation rate constants were $k_{a s}=(6.23 \pm 0.15) \times 10^{3} \mathrm{M}^{-1} \mathrm{~s}^{-1} ; \mathrm{k}_{\text {dis }}=0.0385 \pm 0.005 \mathrm{~s}^{-1}$. All the constants are summarized in Table 3.

420 Finally, we focused on the transfer of Pheo from nanoparticles to LUVs. The stability of the nanoparticles in presence of vesicles was examined by FRET as previously explained. Fluorescence spectra, recorded up to 200 minutes after dilution in presence of LUVs confirms the stability of the nanoparticles over time in our experimental conditions (Figure S1). Moreover, we may note in passing that these data show the absence of transfer of the loaded dyes (DilC and DiOC) from the nanoparticles to the membranes. At this point, the efficiency of the transfer of Pheo from PEO-PCL nanoparticles to membranes has been studied. Preloaded nanoparticles were mixed with vesicles ([lip] $\left.=5 \times 10^{-6} \mathrm{M}\right)$. The fluorescence properties of Pheo in nanoparticles and in LUVs are not different enough to monitor fluorescence changes during transfer. Thus, LUVs were made with lipids conjugated to rhodamine $B$ (ratio 1/100). The transfer was evidenced by registering quenching of the rhodamine fluorescence by FRET, due to the association of Pheo with LUVs and the correlated enhancement of Pheo fluorescence (Figure 6A inset).

The mechanism involved in this transfer (collisions or aqueous diffusion) was deciphered by studying the kinetics. Preloaded nanoparticles ( $[\mathrm{Pheo}]=5 \times 10^{-8} \mathrm{M}$ and $[\mathrm{PEO}-\mathrm{PCL}]=2.5 \times 10^{-6}$ $M$, after mixing) were mixed in a stopped-flow apparatus with rhodamine-doped vesicles ([lip] $=0.6,2.6$ and $10 \times 10^{-5} \mathrm{M}$ after mixing). In these conditions, vesicles and nanoparticles are in excess, justifying the approximations in our theoretical kinetics calculations. After mixing, fluorescence was recorded at an excitation wavelength of $530 \mathrm{~nm}$. The best fits were 
obtained with a monoexponential function according to our models (Figure 6A). The rate constant value was depicted as a function of lipid concentrations (Figure 6B), and its unbounded linear increase led us to conclude that transfer occurred by collision. The association and dissociation rate constants were deduced accordingly with $\mathrm{k}_{\text {lobs }}=$ $(1.33 \pm 0.3) \times 10^{3} \mathrm{M}^{-1} \mathrm{~s}^{-1}$ and $\mathrm{k}_{\text {Dobs }}=0.05 \pm 0.001 \mathrm{~s}^{-1}$.

According to this model, the steady-state constant of transfer can be deduced from the rate constants, where $\mathrm{K}_{\mathrm{T}}=\mathrm{k}_{\text {lobs }} / \mathrm{K}_{\mathrm{Dobs}}$. It follows that $\mathrm{K}_{\mathrm{T}}=(2.66 \pm 0.67) \times 10^{4} \mathrm{M}^{-1}$.

\section{4- Discussion}

Data on cellular penetration are consistent with published results (Luo et al., 2002; Savic et al., 2003) and show that PEO-PCL nanoparticles promote an increase of the speed and the intensity of the Pheo uptake, while they are very poorly internalized themselves. This strongly suggests that the encapsulated dye is no longer associated with the nanoparticle as it enters the cell. PEO-PCL nanoparticles are stable in cell culture media. Transfer of Pheo from the nanoparticle to the cell membrane without release of the photosensitizer in cell culture media provides a possible mechanism.

455 Our in vitro results clearly demonstrate the possibility of a direct transfer of Pheo encapsulated within PEO(5000)-PCL(4000) nanoparticles to membranes. Figure 6B show the rate constant of the transfer plotted vs. lipids concentration. The unbounded linear increase of this function demonstrate that the transfer occurs by collision between nanoparticles and membranes. Further insight into the nature of this transfer can be obtained from the theoretical analysis of the rate. According to the collision model, the second-order rate constants for the association of the Pheo with vesicles can be compared to that of a process limited by diffusion of these species in solution. The theoretical limit is given by:

$\mathrm{k}_{\mathrm{D}}=4 \pi\left(\mathrm{R}_{\mathrm{NP}}+\mathrm{R}_{\mathrm{V}}\right) \times\left(\mathrm{D}_{\mathrm{NP}}+\mathrm{D}_{\mathrm{V}}\right) \times N_{A}$

where, $R_{N P}$ and $R_{V}$ are the radii of the nanoparticles and the vesicles, $D_{N P}$ et $D_{V}$ their diffusion coefficients, and $N_{A}$ the Avogadro's number. Using the Stokes-Einstein equation, $D_{V}$ and $D_{N P}$ can be estimated respectively as $3.66 \times 10^{-12} \mathrm{~m}^{2} / \mathrm{s}$ and $1.46 \times 10^{-11} \mathrm{~m}^{2} / \mathrm{s}$. (Eq. 5 ) gives $\mathrm{k}_{\mathrm{D}}=$ $8.66 \times 10^{4} \mathrm{M}^{-1} \mathrm{~s}^{-1}$ (reported to the lipid content of the vesicles). The experimental rate constant, $1.7 \times 10^{3} \mathrm{M}^{-1} \mathrm{~s}^{-1}$, is consistent with this theoretical limit. The difference may be attributed to the fact that each collision certainly haves a probability $(<1)$ of transferring

470 Pheo successfully. Moreover, comparison between $\mathrm{K}_{\mathrm{L}}, \mathrm{K}_{\mathrm{T}}$ and $\mathrm{K}_{\mathrm{NP}}$ showed that the behavior of the Pheo loaded in nanoparticles is different from that of free Pheo. If the Pheo had been in contact with the aqueous phase, $\mathrm{K}_{\mathrm{T}}$ would have been given by the partition coefficient, i.e. could be deduced from the ratio $\mathrm{K}_{\mathrm{L}} / \mathrm{K}_{\mathrm{NP}}$. Thus, this suggests that the transfer from nanoparticles to vesicles does not occur via aqueous phase and supports the hypothesis that 475 Pheo is transferred by collision between nanoparticles and membranes.

It is then tempting to attribute the increased cellular uptake of Pheo when loaded in PEOPCL nanoparticles to a direct transfer by collision, as demonstrated on membrane-models. This kind of transfer might be facilitated by the PEO corona by inducing dehydration of the lipid bilayer and enhancing membrane permeability (Chen et al., 2008). Thus, free and

480 nanoparticle-loaded Pheo would be expected to follow the same subcellular pathway from the cell membrane, resulting in similar subcellular distributions, as observed in our microscopy experiments. 
In the same manner than for in vitro experiment, one can try to compare the experimental rates obtained in our in cellulo experiments to the theoretical ones. The density of the cells

(radii of which can be estimated around $20 \mu \mathrm{m})$ was determinated $\left(\sim 2 \times 10^{5}\right.$ cells $/ \mathrm{cm}^{2}$ before subculturing, $\sim 1 \times 10^{5}$ cells $/ \mathrm{cm}^{2}$ for experiments). Taking into account that they are immobile, attached to a surface, the problem corresponds to collisions from a half-space. If it occurs by collision, the theoretical rate limiting the process can be estimated to $2.6 \times 10^{-3} \mathrm{~s}^{-1}$, in very good agreement with the experimental rate $\left(1.5 \times 10^{-3} \mathrm{~s}^{-1}\right)$.

490 It is certainly of significance that the hydrophobic DilC and DiOC are transfered neither to model-membranes nor to cells. These results indicate that the structure of the drug (and its depth of insertion within the PEO-PCL nanoparticles) may determine the mechanisms of exchange. It had previously been showed that the incorporation of DilC into a PEO-PCL nanoparticles resulted in very poor cellular internalization of the fluorescent probe in comparison to free DilC (Maysinger et al., 2001). These data also support our assumption of the drug transfer mechanism. Pheo is less hydrophobic than DilC and DiOC and may escape more easily from the nanocarrier core to the cell membrane.

\section{5- CONCLUSIONS}

500 The debates around drug release from block-polymer nanoparticles underscore undoubtedly the complexity of the mechanisms involved. Our study demonstrates that PEO(5000)$\mathrm{PCL}(4000)$ nanoparticles improve the delivery of Pheo to cancer cells. The major mechanism of Pheo drug delivery does not involve the nanoparticles uptake, and may be attributed to the direct transfer of the amphiphilic drug from the nanoparticle to the cell membrane. In these conditions, nanoparticles did not modify the subcellular distribution of the hydrophobic drug. Our results and those of the literature suggest that different mechanisms of drug delivery are possible depending on the drug/polymer couple: i) low penetration of the drug and carrier like for PEO-PCL DiIC/DiOC, ii) drug release followed by transfer to the cell membrane iii) direct transfer of the drug upon contact of the carrier with the cell membrane like for the major part of the Pheo encapsulated in PEO-PCL nanoparticles. This behavior may be critically linked to both the anchoring of the drug to the nanocarrier and the depth of the hydrophobic corona of the nanoparticles. In this view, we think that our work illustrate the great care necessary to address the question of the fundamental description of drug delivery, and the necessity of further additional works on this question.

\section{ACKNOWLEDGMENTS}

This work was funded by the French ANR P2N COPOPDT. All the members on the groups involved in this project are acknowledged for helpful discussions. We also thanks Frédéric Joubert and André Estévez-Torres for helpful reading.

\section{REFERENCES}

Ackroyd, R., Kelty, C., Brown, N., Reed, M., 2001. The history of photodetection and photodynamic therapy. Photochem. Photobiol. 74, 656-669. 
Albertsson, A.-C., Varma, I.K., 2003. Recent developments in ring opening polymerization of lactones for biomedical applications. Biomacromolecules 4, 1466-1486. doi:10.1021/bm034247a

Allen, C., Maysinger, D., Eisenberg, A., 1999. Nano-engineering block copolymer aggregates for drug delivery. Colloids Surf. B Biointerfaces 16, 3-27. doi:10.1016/S09277765(99)00058-2

Allen, C., Yu, Y., Eisenberg, A., Maysinger, D., 1999. Cellular internalization of PCL(20)-bPEO(44) block copolymer micelles. Biochim. Biophys. Acta 1421, 32-38.

Benson, S.W., 1960. The foundations of chemical kinetics. McGraw-Hill.

Brown, S.B., Brown, E.A., Walker, I., 2004. The present and future role of photodynamic therapy in cancer treatment. Lancet Oncol. 5, 497-508. doi:10.1016/S14702045(04)01529-3

Chen, H., Kim, S., Li, L., Wang, S., Park, K., Cheng, J.-X., 2008. Release of hydrophobic molecules from polymer micelles into cell membranes revealed by Forster resonance energy transfer imaging. Proc. Natl. Acad. Sci. U. S. A. 105, 6596-6601. doi:10.1073/pnas.0707046105

Connors, K.A., 1990. Chemical kinetics: the study of reaction rates in solution. VCH, New York, N.Y.

Couleaud, P., Morosini, V., Frochot, C., Richeter, S., Raehm, L., Durand, J.-O., 2010. Silicabased nanoparticles for photodynamic therapy applications. Nanoscale 2, 10831095. doi:10.1039/c0nr00096e

Derycke, A.S.L., de Witte, P.A.M., 2004. Liposomes for photodynamic therapy. Adv. Drug Deliv. Rev. 56, 17-30.

Dougherty, T.J., 1985. Photodynamic therapy. Adv. Exp. Med. Biol. 193, 313-328.

Dougherty, T.J., Gomer, C.J., Henderson, B.W., Jori, G., Kessel, D., Korbelik, M., Moan, J., Peng, Q., 1998. Photodynamic therapy. J. Natl. Cancer Inst. 90, 889-905.

Ehrhart, J., Mingotaud, A.-F., Violleau, F., 2011. Asymmetrical flow field-flow fractionation with multi-angle light scattering and quasi elastic light scattering for characterization of poly(ethyleneglycol-b-e-caprolactone) block copolymer self-assemblies used as drug carriers for photodynamic therapy. J. Chromatogr. A, Flow-Field-Flow Fractionation 1218, 4249-4256. doi:10.1016/j.chroma.2011.01.048

Gibot, L., Lemelle, A., Till, U., Moukarzel, B., Mingotaud, A.-F., Pimienta, V., Saint-Aguet, P., Rols, M.-P., Gaucher, M., Violleau, F., Chassenieux, C., Vicendo, P., 2014. Polymeric micelles encapsulating photosensitizer: structure/photodynamic therapy efficiency relation. Biomacromolecules 15, 1443-1455. doi:10.1021/bm5000407

Hoebe, R.A., Van Oven, C.H., Gadella, T.W.J., Jr, Dhonukshe, P.B., Van Noorden, C.J.F., Manders, E.M.M., 2007. Controlled light-exposure microscopy reduces photobleaching and phototoxicity in fluorescence live-cell imaging. Nat. Biotechnol. 25, 249-253. doi:10.1038/nbt1278

Kazunori, K., Glenn S., K., Masayuki, Y., Teruo, O., Yasuhisa, S., 1993. Block copolymer micelles as vehicles for drug delivery. J. Controlled Release, Special Issue Proceedings of the Second European Symposium on Controlled Drug Delivery 24, 119-132. doi:10.1016/0168-3659(93)90172-2

Kerdous, R., Heuvingh, J., Bonneau, S., 2011. Photo-dynamic induction of oxidative stress within cholesterol-containing membranes: Shape transitions and permeabilization. Biochim. Biophys. Acta BBA - Biomembr. 1808, 2965-2972. doi:10.1016/j.bbamem.2011.08.002 
Kim, S., Shi, Y., Kim, J.Y., Park, K., Cheng, J.-X., 2010. Overcoming the barriers in micellar drug delivery: loading efficiency, in vivo stability, and micelle-cell interaction. Expert Opin. Drug Deliv. 7, 49-62. doi:10.1517/17425240903380446

Kim, Y., Pourgholami, M.H., Morris, D.L., Stenzel, M.H., 2011. An optimized RGD-decorated micellar drug delivery system for albendazole for the treatment of ovarian cancer: from RAFT polymer synthesis to cellular uptake. Macromol. Biosci. 11, 219-233. doi:10.1002/mabi.201000293

Knop, K., Mingotaud, A.-F., El-Akra, N., Violleau, F., Souchard, J.-P., 2009. Monomeric pheophorbide(a)-containing poly(ethyleneglycol-b-epsilon-caprolactone) micelles for photodynamic therapy. Photochem. Photobiol. Sci. Off. J. Eur. Photochem. Assoc. Eur. Soc. Photobiol. 8, 396-404. doi:10.1039/b811248g

Konan, Y.N., Gurny, R., Allémann, E., 2002. State of the art in the delivery of photosensitizers for photodynamic therapy. J. Photochem. Photobiol. B 66, 89-106.

Kuntsche, J., Freisleben, I., Steiniger, F., Fahr, A., 2010. Temoporfin-loaded liposomes: physicochemical characterization. Eur. J. Pharm. Sci. Off. J. Eur. Fed. Pharm. Sci. 40, 305-315. doi:10.1016/j.ejps.2010.04.005

Kuzelová, K., Brault, D., 1994. Kinetic and equilibrium studies of porphyrin interactions with unilamellar lipidic vesicles. Biochemistry (Mosc.) 33, 9447-9459.

Levy, J.G., Obochi, M., 1996. New applications in photodynamic therapy. Introduction. Photochem. Photobiol. 64, 737-739.

Li, B., Moriyama, E.H., Li, F., Jarvi, M.T., Allen, C., Wilson, B.C., 2007. Diblock copolymer micelles deliver hydrophobic protoporphyrin IX for photodynamic therapy. Photochem. Photobiol. 83, 1505-1512. doi:10.1111/j.1751-1097.2007.00194.x

Liu, J., Xiao, Y., Allen, C., 2004. Polymer-drug compatibility: a guide to the development of delivery systems for the anticancer agent, ellipticine. J. Pharm. Sci. 93, 132-143. doi:10.1002/jps.10533

Loew, S., Fahr, A., May, S., 2011. Modeling the release kinetics of poorly water-soluble drug molecules from liposomal nanocarriers. J. Drug Deliv. 2011, 376548. doi:10.1155/2011/376548

Luo, L., Tam, J., Maysinger, D., Eisenberg, A., 2002. Cellular internalization of poly(ethylene oxide)-b-poly(epsilon-caprolactone) diblock copolymer micelles. Bioconjug. Chem. 13, 1259-1265.

Mabrouk, E., Bonneau, S., Jia, L., Cuvelier, D., Li, M.-H., Nassoy, P., 2010. Photosensitization of polymer vesicles: a multistep chemical process deciphered by micropipette manipulation. Soft Matter 6, 4863-4875. doi:10.1039/c002065f

Maeda, H., Wu, J., Sawa, T., Matsumura, Y., Hori, K., 2000. Tumor vascular permeability and the EPR effect in macromolecular therapeutics: a review. J. Control. Release Off. J. Control. Release Soc. 65, 271-284.

Maysinger, D., Berezovska, O., Savic, R., Soo, P.L., Eisenberg, A., 2001. Block copolymers modify the internalization of micelle-incorporated probes into neural cells. Biochim. Biophys. Acta 1539, 205-217.

Miller, J.W., Schmidt-Erfurth, U., Sickenberg, M., Pournaras, C.J., Laqua, H., Barbazetto, I., Zografos, L., Piguet, B., Donati, G., Lane, A.M., Birngruber, R., van den Berg, H., Strong, A., Manjuris, U., Gray, T., Fsadni, M., Bressler, N.M., Gragoudas, E.S., 1999. Photodynamic therapy with verteporfin for choroidal neovascularization caused by age-related macular degeneration: results of a single treatment in a phase 1 and 2 study. Arch. Ophthalmol. 117, 1161-1173. 
Mojzisova, H., Bonneau, S., Vever-Bizet, C., Brault, D., 2007a. The pH-dependent distribution of the photosensitizer chlorin e6 among plasma proteins and membranes: a physicochemical approach. Biochim. Biophys. Acta 1768, 366-374. doi:10.1016/j.bbamem.2006.10.009

Mojzisova, H., Bonneau, S., Vever-Bizet, C., Brault, D., 2007b. Cellular uptake and subcellular distribution of chlorin e 6 as functions of $\mathrm{pH}$ and interactions with membranes and lipoproteins. Biochim. Biophys. Acta 1768, 2748-2756. doi:10.1016/j.bbamem.2007.07.002

Owens, D.E., 3rd, Peppas, N.A., 2006. Opsonization, biodistribution, and pharmacokinetics of polymeric nanoparticles. Int. J. Pharm. 307, 93-102. doi:10.1016/j.ijpharm.2005.10.010

Petr Praus, E.K., 2007. Advanced Microfluorescence Methods in Monitoring Intracellular Uptake of Antisense Oligonucleotides. Curr. Org. Chem. - CURR ORG CHEM 11. doi:10.2174/138527207780368210

Savic, R., Luo, L., Eisenberg, A., Maysinger, D., 2003. Micellar nanocontainers distribute to defined cytoplasmic organelles. Science 300, 615-618. doi:10.1126/science.1078192

Spikes, J.D., 1982. Photodynamic Reactions in Photomedicine, in: Regan, J.D., Parrish, J.A. (Eds.), The Science of Photomedicine, Photobiology. Springer US, pp. 113-144.

Stenzel, M.H., 2008. RAFT polymerization: an avenue to functional polymeric micelles for drug delivery. Chem. Commun. Camb. Engl. 3486-3503. doi:10.1039/b805464a

Uhrich, K.E., Cannizzaro, S.M., Langer, R.S., Shakesheff, K.M., 1999. Polymeric systems for controlled drug release. Chem. Rev. 99, 3181-3198.

Van den Bergh, H., 1998. On the evolution of some endoscopic light delivery systems for photodynamic therapy. Endoscopy 30, 392-407. doi:10.1055/s-2007-1001289

Wattendorf, U., Merkle, H.P., 2008. PEGylation as a tool for the biomedical engineering of surface modified microparticles. J. Pharm. Sci. 97, 4655-4669. doi:10.1002/jps.21350

Wei, X., Gong, C., Gou, M., Fu, S., Guo, Q., Shi, S., Luo, F., Guo, G., Qiu, L., Qian, Z., 2009. Biodegradable poly(epsilon-caprolactone)-poly(ethylene glycol) copolymers as drug delivery system. Int. J. Pharm. 381, 1-18. doi:10.1016/j.ijpharm.2009.07.033

Yokoyama, M., 2010. Polymeric micelles as a new drug carrier system and their required considerations for clinical trials. Expert Opin. Drug Deliv. 7, 145-158. doi:10.1517/17425240903436479 
TABLES

\begin{tabular}{|c|c|c|c|}
\hline \multicolumn{2}{|c|}{} & Fluorescence & Extraction \\
\hline Nanoparticles & $\mathrm{k}_{1}\left(\mathrm{~s}^{-1}\right)$ & $1.6 \times 10^{-3}$ & $1.4 \times 10^{-3}$ \\
\cline { 2 - 4 } loaded Pheo & $\mathrm{k}_{2}\left(\mathrm{~s}^{-1}\right)$ & $1.3 \times 10^{-4}$ & $1.4 \times 10^{-4}$ \\
\hline Free Pheo & $\left.\mathrm{k}^{-1} \mathrm{~s}^{-1}\right)$ & $3.0 \times 10^{-4}$ & $3.8 \times 10^{-4}$ \\
\hline
\end{tabular}

Table 1: Table of the internalization rates of free Pheo and of nanoparticles-loaded Pheo within MCF-7 cells.

\begin{tabular}{|l|l|}
\hline Sample & Fluorescence lifetime \\
\hline Nanoparticle - DiOC in aqueous medium & DiOC: $2.5 \mathrm{~ns}$ \\
\hline Nanoparticle - DilC/DiOC in aqueous medium & DiOC $: 0.5 \mathrm{~ns}$ - DilC $: 1.45 \mathrm{~ns}$ \\
\hline Nanoparticle - DilC/DiOC incubated with MCF-7 (4h) & Non significant - signal too weak \\
\hline Nanoparticle - DilC/DiOC incubated with MCF-7 24h & DiOC $: 1 \mathrm{~ns}$ - DilC $: 1.5 \mathrm{~ns}$ \\
\hline
\end{tabular}

Table 2: Values of the fluorescence lifetime of DiOC and/or DilC in our various experimental conditions.

\begin{tabular}{|c|c|c|c|c|}
\hline \multirow{2}{*}{ Vesicles $(\mathrm{V})$} & $\mathrm{k}_{\text {on }}\left(\mathrm{M}^{-1} \cdot \mathrm{s}^{-1}\right)$ & $\mathrm{k}_{\text {off }}\left(\mathrm{s}^{-1}\right)$ & $\mathrm{k}_{\text {flip }}\left(\mathrm{s}^{-1}\right)$ & $\mathrm{K}_{\mathrm{L}}\left(\mathrm{M}^{-1}\right)$ \\
\cline { 2 - 5 } & $(5.85 \pm 0.4) \times 10^{2}$ & $(3.35 \pm 0.5) \times 10^{-4}$ & $(5 \pm 0.6) \times 10^{-4}$ & $(1.14 \pm 0.05) \times 10^{6}$ \\
\hline $\begin{array}{c}\text { PEO-PCL } \\
\begin{array}{c}\text { Nanoparticles } \\
(\mathrm{NP})\end{array}\end{array}$ & $\mathrm{k}_{\text {as }}\left(\mathrm{M}^{-1} \cdot \mathrm{s}^{-1}\right)$ & $\mathrm{k}_{\text {dis }}\left(\mathrm{s}^{-1}\right)$ & - & $\mathrm{K}_{\mathrm{NP}}\left(\mathrm{M}^{-1}\right)$ \\
\cline { 2 - 5 } & $(6.23 \pm 0.15) \times 10^{3}$ & $0.0385 \pm 0.005$ & - & $(1.07 \pm 0.2) \times 10^{5}$ \\
\hline $\begin{array}{c}\text { Transfer } \\
(\mathrm{NP} \rightarrow \mathrm{V})\end{array}$ & $\mathrm{k}_{\mathrm{l}}\left(\mathrm{M}^{-1} \cdot \mathrm{s}^{-1}\right)$ & $\mathrm{k}_{\mathrm{D}}\left(\mathrm{s}^{-1}\right)$ & - & $\mathrm{K}_{\mathrm{T}}\left(\mathrm{M}^{-1}\right)$ \\
\cline { 2 - 5 } & $(1.33 \pm 0.3) \times 10^{3}$ & $0.05 \pm 0.001$ & - & $(2.66 \pm 0.67) \times 10^{4}$ \\
\hline
\end{tabular}

665 Table $3:$ Values of the rate constants obtained in the kinetics experiments. 

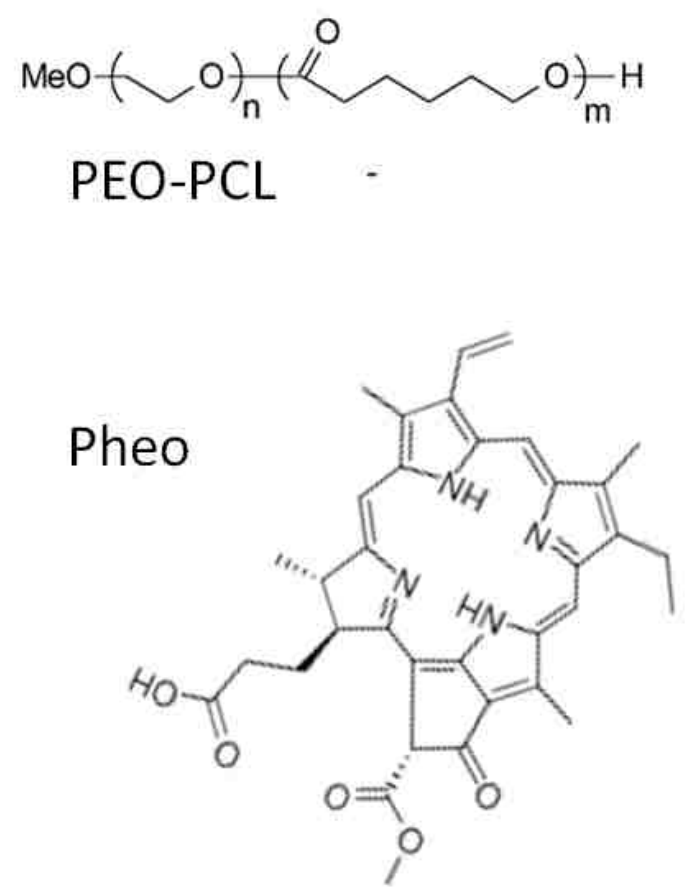

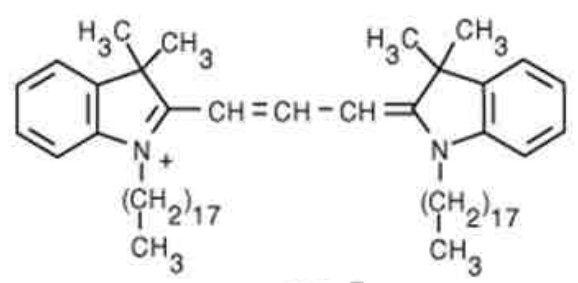

DilC $\mathrm{ClO}_{4}$<smiles></smiles>

DiOC

Figure 1: Figure 1: Formula of the polymer (poly(ethylene oxide)-poly(E-caprolactone) [PEO(5000)-PCL(4000)]) and of the dyes used. 

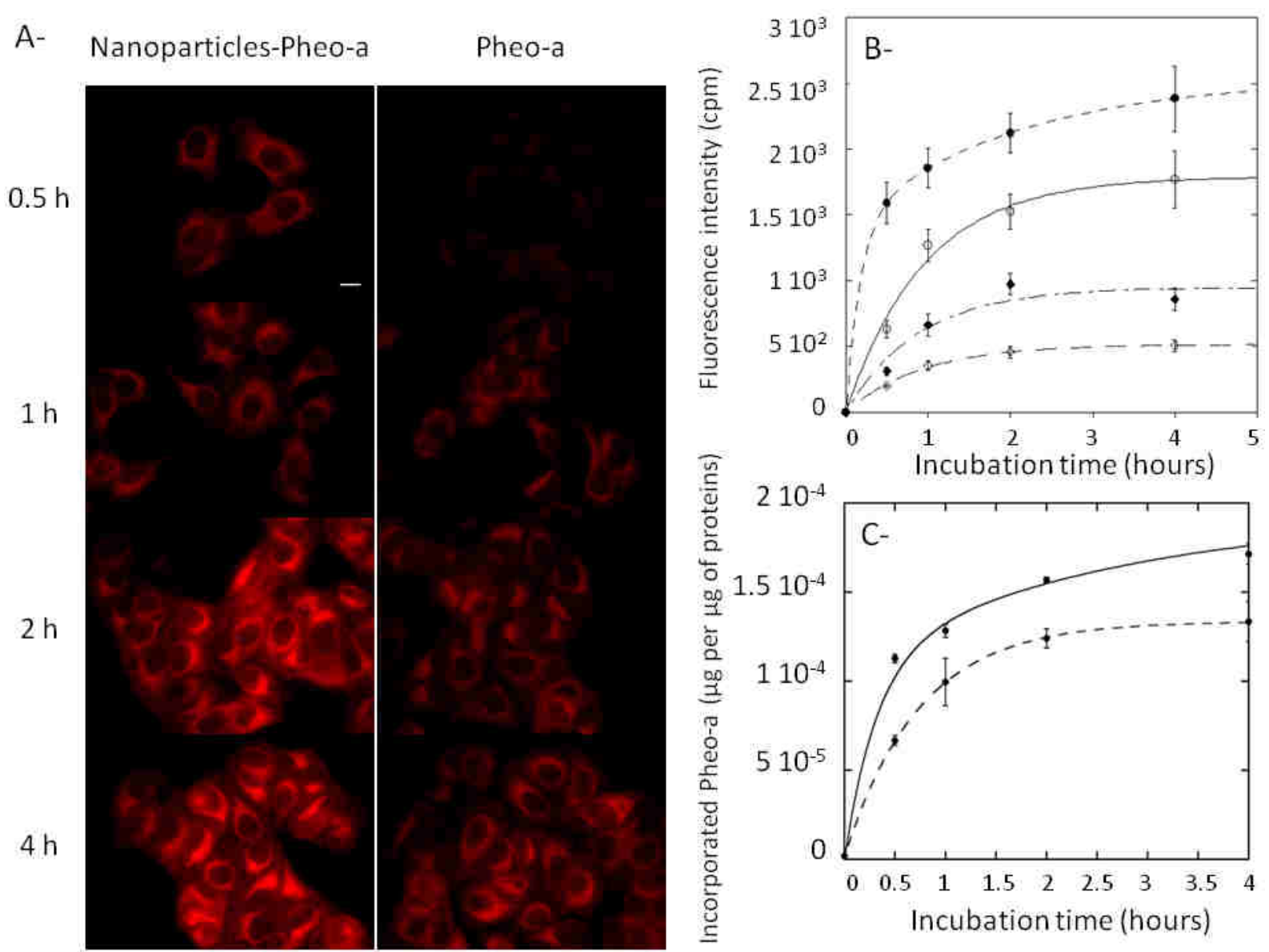

670 Figure 2: Effect of nanoparticle preloading on Pheo cellular incorporation. (A) Pheo cellular localization. After $30 \mathrm{~min}, 1,2$ or $4 \mathrm{~h}$ of incubation, the red fluorescence of Pheo was observed). [Pheo] $=10^{-6} \mathrm{M}$. Cells were incubated with nanoparticle-loaded Pheo (left column) and with free Pheo (right column). Scale bar $=10 \mu \mathrm{m} .(B, C)$ Quantification of Pheo incorporation into cells. The curves correspond to the best fit with a mono-or bi-exponential function for incubations with free Pheo or with nanoparticle-loaded Pheo, respectively. The related rate constants are summarized in Table 1. (B and C) Kinetics of the cellular uptake. (B) Fluorescence microscopy experiments. Incubations where performed with free (white symbols) or nanoparticle-loaded Pheo (black symbols) at a concentration of $10^{-6} \mathrm{M}$ (circles) or $10^{-7} \mathrm{M}$ (diamonds). (C) Extraction experiments. Incubations where performed with free or 680 nanoparticle-loaded Pheo at $10^{-6} \mathrm{M}$. The amount of photosensitizer incorporated into cells was determined by fluorescence measurements on the extracts as described in the text. Data are normalized to cellular protein content. 

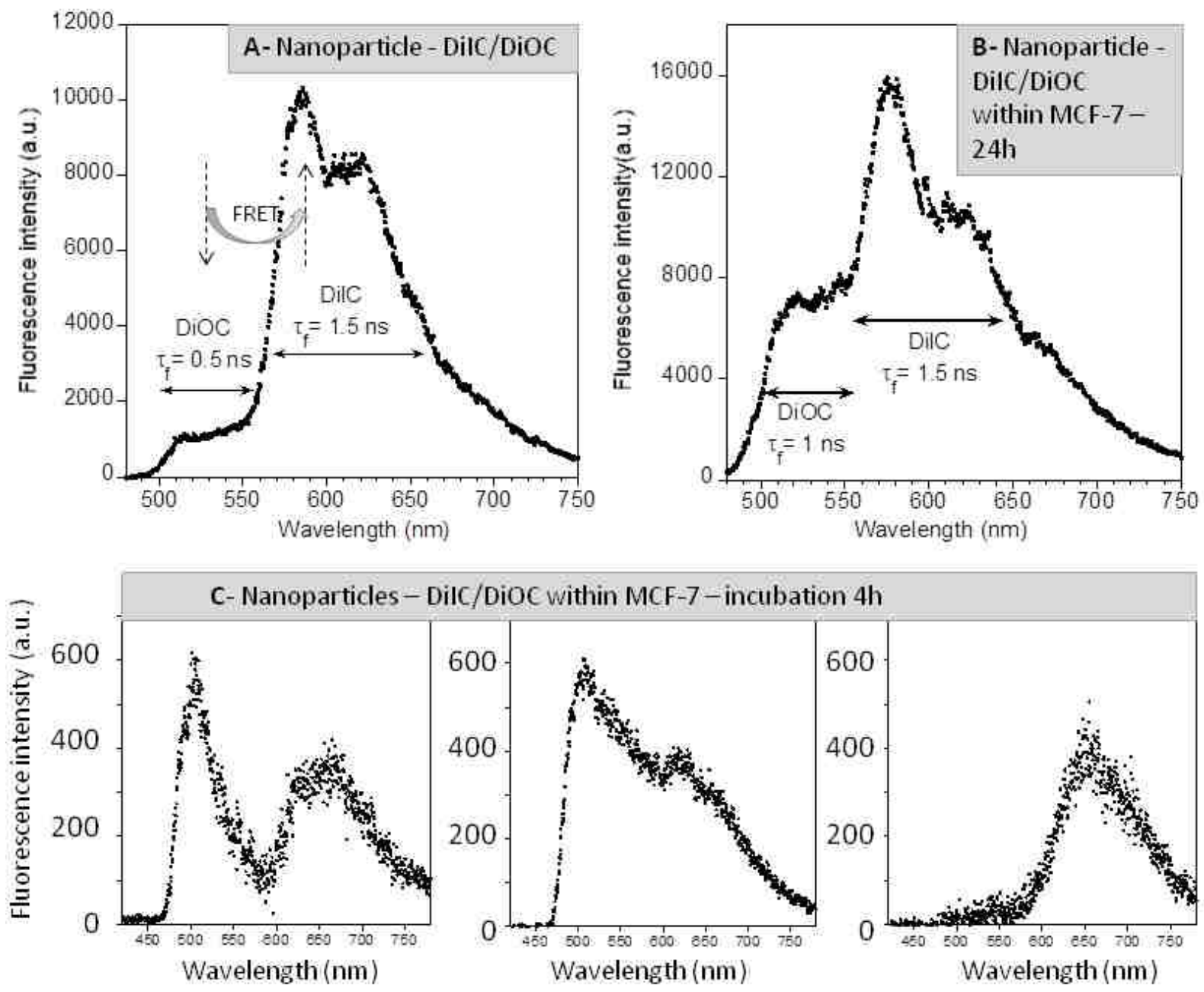

Figure 3: Cellular uptake and stability of PEO-PCL nanoparticles. A- Fluorescence spectrum of an aqueous medium of encapsulated DiIC/DiOC, exhibiting the FRET characteristics. BSimilar fluorescence spectrum within a cell incubated $24 \mathrm{~h}$ with the nanoparticles loaded with DiIC/DiOC, showing a less important FRET. C- Weak signals recorded in some cells incubated $4 h$ with nanoparticles loaded with DilC/DiOC. 
A-

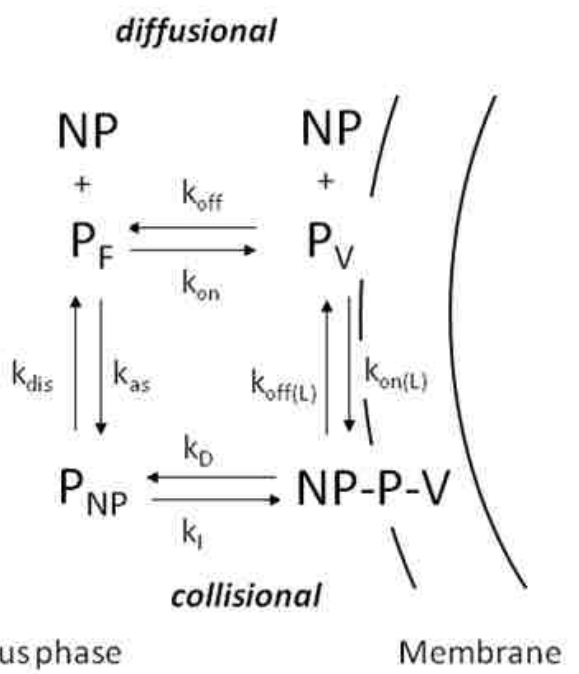

B- $\quad 35$

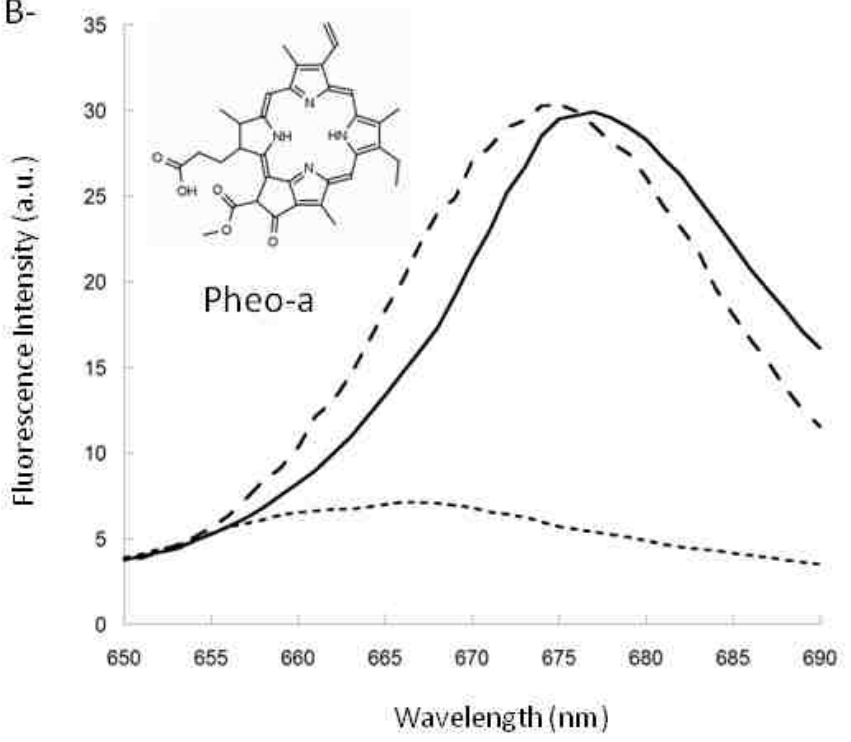

Figure 4: Pheo in various environments. A- Kinetic model of Pheo transfer from preloaded nanoparticles to lipid vesicles. The scheme outlines the kinetic models for a collisional mechanism of transfer and for a diffusional process via the aqueous phase. $N P, P_{F}$ and $V$ represent the free aqueous concentrations of nanoparticles, Pheo and vesicles, respectively. $P_{N P}, P_{V}$, and NP-P-V are the concentrations of the Pheo associated to nanoparticles and to the vesicles, and the pheo-nanoparticle-vesicle complex. Rate constants are depicted by $k$ with subscripted indices. B-Spectra of the Pheo in PBS (dotted line), DOPC-vesicles (solid line) and nanoparticles (dashed line) of PEO-PCO block-polymer. Excitation wavelength $410 \mathrm{~nm}$. 

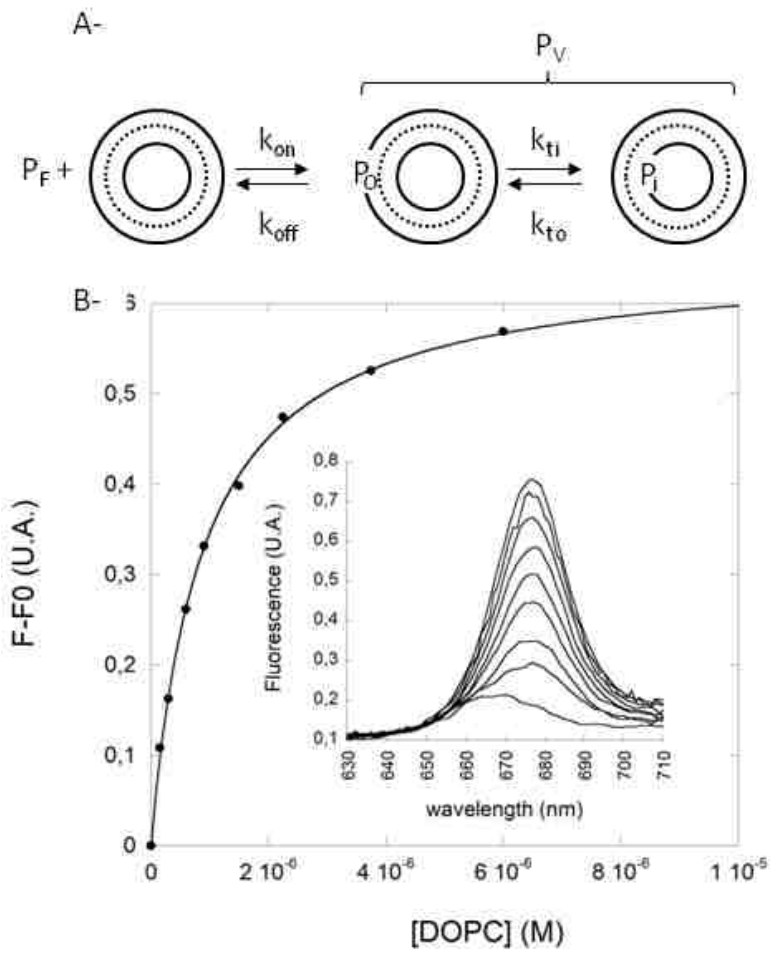

C-
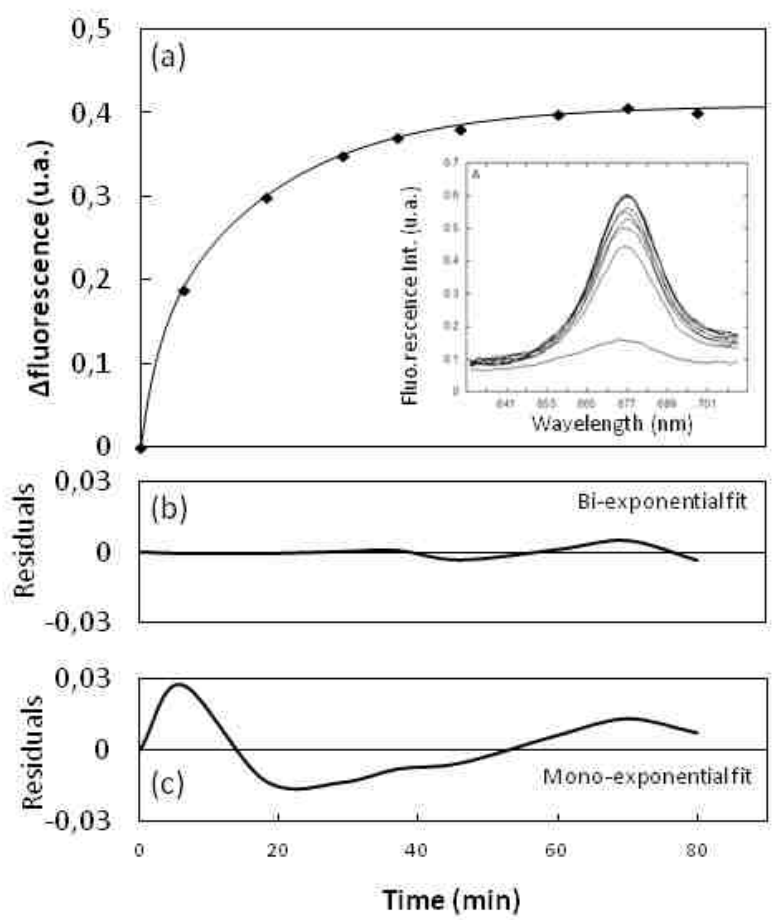

Figure 5: Association of the Pheo with vesicles. A- Scheme of the kinetics of interaction of Pheo with membrane models (LUVS). B- Evolution of fluorescence emission of Pheo $\left(3.75 \times 10^{-8}\right.$ M) upon incorporation into LUVs. The excitation wavelength was set at $410 \mathrm{~nm}$. Experimental data are fitted according to an association constant $K_{L}$ of $1.14 \times 10^{6} \mathrm{M}^{-1}$. (inset) Fluorescence emission spectra. C- (a) Fluorescence changes accompanying the association of Pheo (3.75 $\times 10-8 \mathrm{M})$ to LUVs $\left(5 \times 10^{-6} \mathrm{M}\right)$. (b) Residuals from a biexponential fit of the signal shown in (a). (c) Residuals from a mono-exponential fit. Excitation wavelength: $410 \mathrm{~nm}$. 
A-

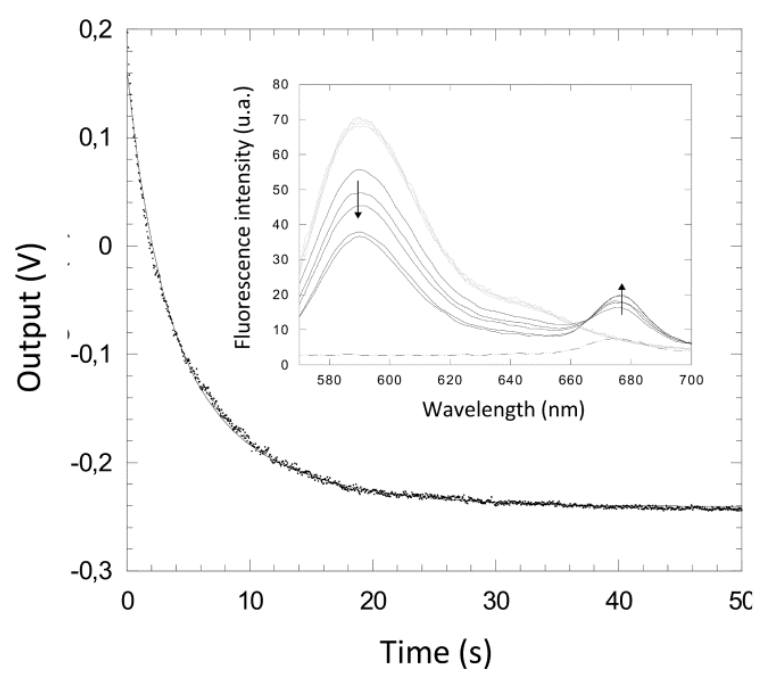

B-

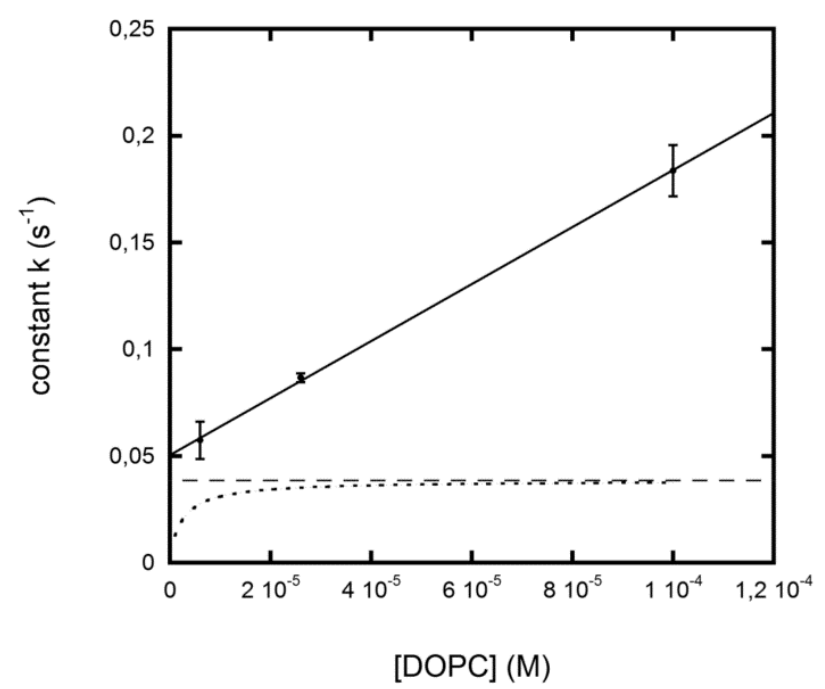

Figure 6: Transfer of the Pheo from nanoparticles to model-membranes. A-Evolution of the fluorescence of rhodamine-doped vesicles after mixing with Pheo-preloaded nanoparticles. The signal is monoexponential. ([lip] $=2.6 \times 10^{-5} \mathrm{M},[\mathrm{pol}]=2.5 \times 10^{-6} \mathrm{M},[$ Pheo $]=5 \times 10^{-8} \mathrm{M}$ ). (Inset): Quenching of rhodamine $B$ fluorescence excited at $530 \mathrm{~nm}$ following association of Pheo. Fluorescence spectra of rhodamine $B\left(10^{-8} \mathrm{M}\right)$ as a function of increasing amounts of NP-Pheo expressed in quantities of added polymer [PEO-PCL] /[Lip] $=0,0.25,0.5,1,2$ in the direction of the arrow. B- Evolution of the rate constant of transfer of Pheo from nanoparticles to vesicles as a function of lipid concentration. The solid line corresponds to the best fit according with the collisional hypothesis. The dotted line corresponds to the diffusion hypothesis, and the dashed line to its maximum limit. 


\section{Supplementary materials}

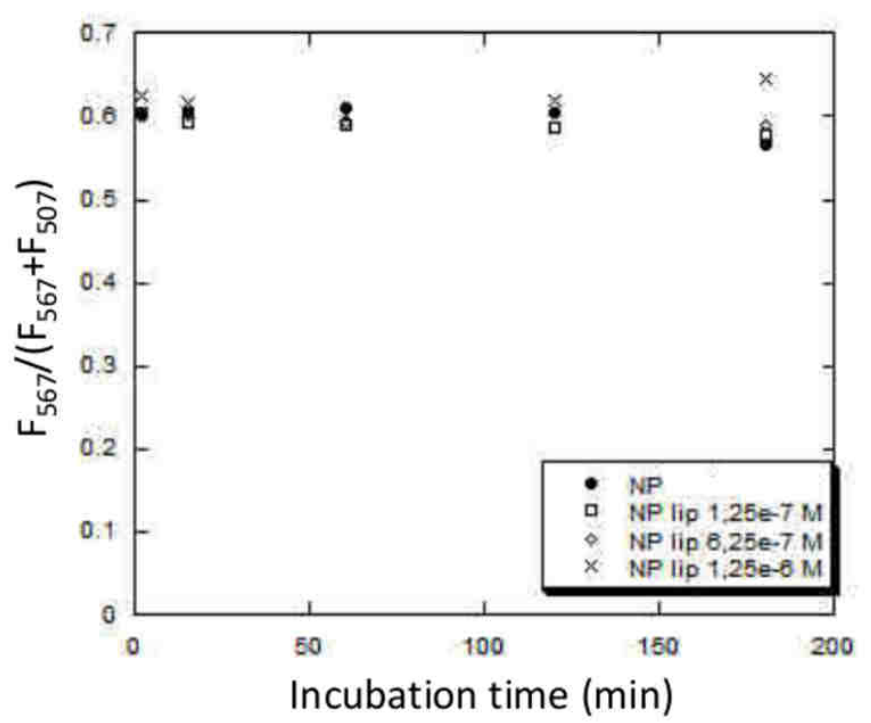

Figure S1: Efficiency of the FRET between DilC and DiOC, of which stability over time signs the good encapsulation of the couple DiIC/DiOC within the intact nanoparticles, after dilution in vesicles preparations. 